www.jmscr.igmpublication.org

Impact Factor 5.84

Index Copernicus Value: 71.58

ISSN (e)-2347-176x ISSN (p) 2455-0450

crossref DOI: _https://dx.doi.org/10.18535/jmscr/v5i9.69

\title{
A Study of Pathological Evaluation and Management of Thyroid Nodule in Western Rajasthan
}

\author{
Authors \\ Sanjay Kumar Saini ${ }^{1}$, Ashok Parmar ${ }^{2}$, Tapasya $^{3^{*}}$ \\ ${ }^{1}$ Senior Resident, ${ }^{2}$ Professor \& Head, Department of Surgery, Sardar Patel Medical College \& P.B.M. \\ Hospital, Bikaner, Rajasthan \\ ${ }^{3 *}$ M.D. Pathology \\ Corresponding Author \\ Tapasya*
}

\begin{abstract}
Background: The diseases of thyroid from a major share of head and neck surgery. Clinical examination although very accurate in most cases, is inadequate in most areas especially in staging of thyroid malignancies and in detecting the multi nodularity of the gland.

Methods: this is Cross sectional record based study.12 months (August 2015 to July 2016) at Dept.of Surgery, S.P. Medical College and P.B. M Hospital, Bikaner.

Results: Majority (90\%) patients were Benign and $10 \%$ patients were malignant. Maximum $64 \%$ patients were operated with hemithyroidectomy whereas $16 \%$ had nodule excision and $14 \%$ were operated with total thyroidectomy. $8 \%$ patients had near total or subtotal thyroidectomy. $4 \%$ had total thyroidectomy with MRND and only $2 \%$ had isthmectomy.

Conclusion: Most of thyoid swelling were benign.

Keywords: Thyroid Swelling; Goiter; FNAC.
\end{abstract}

\section{INTRODUCTION}

The diagnosis of thyroid lesions using aspiration cytology was first reported by Martin and Ellis in $1930^{1}$. The routine use of fine needle aspiration cytology (FNAC) in the assessment of thyroid nodules has reduced the number of patients subjected to thyroidectomy for benign diseases of the thyroid. ${ }^{2,3,4}$ As a result, the incidence of malignancy at thyroidectomy has increased from $5-10 \%$ to $30-50 \%$ in the recent years. ${ }^{5,6}$ This relatively simple procedure has assumed a dominant role in determining the management of patients with thyroid nodules. ${ }^{7,8}$ However, the success of FNAC is contingent upon several important contributing influences including aspirator experience $9,10,11$, skillful cytological interpretation and a rational analysis based upon a synthesis of cytological and clinical information in the context of an individual patient ${ }^{10,11}$.

Solitary thyroid nodule still remains a mystery for surgeons and pathologists in these days of recent advances, because of the variations in pathological findings presented by it. Sometimes it causes no symptoms and is very small clinically but turns out to be fatal because of its highly malignant nature. On other hand clinically a large solitary nodule, after its removal proves to be benign pathologically. Thus it displays a great variety in 


\section{JMSCR Vol||05||Issue||09||Page 27768-27772||September}

its ultimate outcome though clinical presentation remains same each time.

\section{MATERIAL AND METHODS}

Study Design: Cross sectional record based study. Study Duration: 12 months (August 2015 to July 2016).

Study Place: Dept. of Surgery, S.P.Medical College and P.B.M Hospital, Bikaner

Study Population: All patients reporting with thyroid swelling

Sample Size: 50 patients reporting to the Surgery dept. within study duration and eligible as per inclusion criteria were included in the study.

Sampling Method: Convenience sampling

\section{Inclusion Criteria}

- Patients admitted with complaint of thyroid swelling.

\section{Exclusion Criteria}

- Children with neck swelling (below 10 year).

- Head \& Neck swelling other than thyroid origin

- Patients refusing for investigation/ management

\section{Data Analysis}

The information thus collected was entered into Microsoft excel sheet thereafter with help of SPSS 22.0 data were analyzed with the help of frequencies, figures, proportions, measures of central tendency, appropriate statistical test wherever required.

\section{RESULTS}

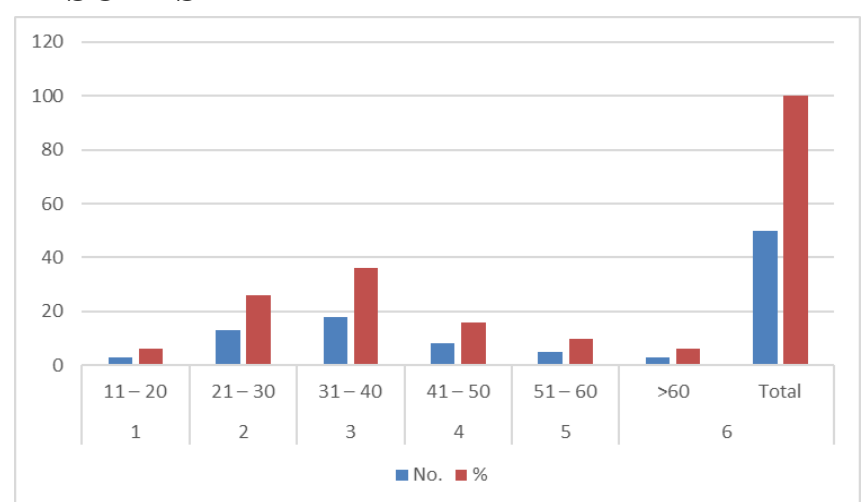

Fig.1: Distribution of study population according to Age
Distribution of study population according to $\operatorname{sex}(\mathrm{N}=50)$

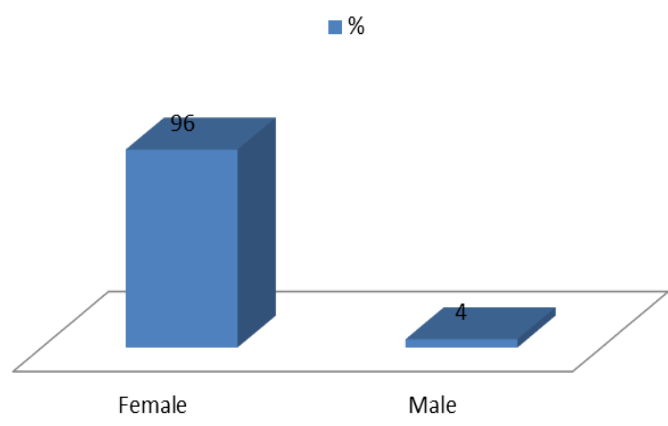

Fig.2: Distribution of Study Population according to Sex

Table-1: Distribution of study population according to FNAC report

\begin{tabular}{|l|c|c|c|}
\hline S.N. & FNAC & No. & $\%$ \\
\hline 1 & Benign & 45 & 90 \\
\hline 2 & Malignant & 5 & 10 \\
\hline & Total & 50 & 100.0 \\
\hline
\end{tabular}

Table-1. shows that majority (90\%) patients were benign and $10 \%$ patients were malignant.

Table-2: Distribution of study population according to Histopathology report

\begin{tabular}{|c|l|l|l|}
\hline S.N. & Histopathology & No. & $\%$ \\
\hline 1. & Benign & 45 & 90 \\
\hline 2. & Malignant & 5 & 10 \\
\hline 3. & Papillary Ca. & 4 & 8 \\
\hline 4. & Follicular Ca. & 1 & 2 \\
\hline 5. & Medullary Ca. & 0 & 0 \\
\hline 6. & Malignant Lymphoma & 0 & 0 \\
\hline 7. & Anaplastic & 0 & 0 \\
\hline
\end{tabular}

Table-2 shows that among 50 cases, 90\% were diagnosed with benign swellings whereas $10 \%$ had malignant swellings. Out of $10 \%$ malignant swellings, $8 \%$ had papillary carcinoma and 2\% had follicular carcinoma. 
Table-3: Thyroid Profile according to Histopathology.

\begin{tabular}{|l|c|c|c|c|c|c|c|c|}
\hline \multirow{3}{*}{ Histopathology } & \multicolumn{9}{|c|}{ TFT } & \multicolumn{2}{c|}{ Total } \\
\cline { 2 - 9 } & \multicolumn{2}{|c|}{ Euthyroid } & \multicolumn{2}{|c|}{ Hypothyroid } & \multicolumn{2}{c|}{ Hyperthyroid } & \multicolumn{2}{c|}{$\%$} \\
\cline { 2 - 9 } & No. & $\%$ & No. & $\%$ & No. & $\%$ & No. & 90 \\
\hline Benign & 31 & 68.89 & 12 & 26.67 & 2 & 4.44 & 45 & 10 \\
\hline Malignant & 3 & 60.0 & 2 & 40.0 & 0 & 0.0 & 5 & 100.0 \\
\hline Total & 34 & 68.0 & 14 & 28.0 & 2 & 4.0 & 50 & 10 \\
\hline
\end{tabular}

Table-3 shows thyroid profile status of patients more prevalent among euthyroid patients $(60.0 \%)$. according to histopathology report. Benign swellings were more prevalent among euthyroid patients $(68.89 \%)$. Malignant swellings were also

The statistical association between thyroid profile and sex of study participants was found to be statistically insignificant $\left(\chi^{2}=9.753, \mathrm{df}=2, \mathrm{p}<0.05\right)$.

Table-4: Distribution of study population according to Procedure Performed.

\begin{tabular}{|l|c|c|c|}
\hline S.N. & Procedure & No. & $\%$ \\
\hline 1 & Hemithyroidectomy & 32 & 64 \\
\hline 2 & Near Total/Sub Total thyroidectomy & 4 & 8 \\
\hline 3 & Total thyroidectomy & 7 & 14 \\
\hline 4 & Nodule excision & 4 & 16 \\
\hline 5 & Total thyroidectomy with MRND & 2 & 4 \\
\hline 6 & Isthmectomy & 1 & 2 \\
\hline & Total & 50 & 100.0 \\
\hline
\end{tabular}

Table-4 shows that maximum $64 \%$ patients were operated with hemithyroidectomy whereas $16 \%$ had nodule excision and $14 \%$ were operated with total thyroidectomy. $8 \%$ patients had near total or subtotal thyroidectomy. $4 \%$ had total thyroidectomy with MRND and only $2 \%$ had isthmectomy.

\section{DISCUSSION}

In present study, maximum $36 \%$ belonged to 31 40 years age group followed by $26 \%$ individuals in 21-30 years age group. Similar findings were observed by Borgohain R et $\mathrm{al}(2013)^{50}$ in a cross sectional study in the department of ENT - Head and Neck Surgery, Guwahati Medical College \& Hospital, Guwahati, Assam, from January 2012 to December 2013 (2 years). In this series of 122 thyroid swellings, patients were grouped in age groups of $0-20 ; 21-40 ; 41-60$ and $61-80$ years \& patients in each age group were $9 \% ; 50 \% ; 37 \%$ and $4 \%$ respectively. Most of the patients were in the age group of 21-40 years. Whereas Srivastava $\mathrm{C}$ et al $(2015)^{13}$ found that most common age group affected was 51-60 years followed by 41-50 years and RajnishN et al (2015) ${ }^{14}$ found that out of 16933 cancer patients, 128 patients suffered from thyroid disorders and the prevalence of thyroid disorders was significantly higher in higher aged

(>31 years) patients as compared to lower aged (>30 years) patients $\left(14.1 \%\right.$ vs. $85.9 \%, \chi^{2}$ $=132.30, p<0.001)$. Similarly in the present study, when thyroid profile of patients was studied according to their age, most patients in all age groups were euthyroid, the statistical association between thyroid profile and age of study participants was found to be statistically significant $\left(\chi^{2}=16.679, \mathrm{df}=10, \mathrm{p}<0.05\right)$.

In the present study, $96 \%$ were females and $4 \%$ were males whereas Thomas $\mathrm{T}$ et al $(2014)^{51}$ observed that in 144 patients with cytological proven HT/lymphocytic thyroiditis, $90 \%$ of the patients were females and most of them presented within five years of onset of symptoms.

In the present study, 64\% patients were operated with hemithyroidectomy whereas $16 \%$ had nodule excision and $14 \%$ were operated with total thyroidectomy. $8 \%$ patients had near total or subtotal thyroidectomy. $4 \%$ had total thyroidectomy with MRND and only $2 \%$ had isthmectomy. $84 \%$ patients were having pain as prominent post operative symptom followed by $24 \%$ patients who experienced cough, $16 \%$ having carpopedal spasm, 14\% having dysphagia and a few patients reported hoarseness (2\%) and cramps 
(4\%) also.78\% patients faced no problem post operatively, $22 \%$ developed hypothyroidism, $18 \%$ developed hypoparathyroidism, 10\% developed hypertrophic scar on site of surgery. Recurrent laryngeal nerve palsy as well as hematoma was seen in $2 \%$ patients each. None of the operated cases reported wound infection. Among 50 cases, $88 \%$ had negative suction drain removal within 46 post operative day. $96 \%$ patients stayed in hospital for $<7$ days. $78 \%$ of 50 patients had experienced no post operative complications whereas $22 \%$ faced one or the other complications. The statistical association between age group and occurrence of post-operative complications was found to be statistically insignificant $\left(\chi^{2}=0.423, \mathrm{df}=5, \mathrm{p}>0.05\right)$. Goel MM et $\mathrm{al}^{15}$ concluded that FNAC alone was sufficient for the diagnosis of cutaneous metastases of thyroid carcinoma, thus eliminating the need for confirmatory surgical biopsy and immunohistochemistry.

\section{CONCLUSION}

Majority (90\%) patients were Benign and 10\% patients were malignant and Maximum 64\% patients were operated with hemithyroidectomy whereas $16 \%$ had nodule excision and $14 \%$ were operated with total thyroidectomy. $8 \%$ patients had near total or subtotal thyroidectomy. $4 \%$ had total thyroidectomy with MRND and only $2 \%$ had isthmectomy.

\section{BIBLIOGRAPHY}

1. Martin HE, Ellis EB. Biopsy by needle puncture and aspiration. Ann Surg 1930;92:169-81.

2. Bottles K, Miller TR, Cohen MB. Fine needle aspiration biopsy: has its time come? Am J Med.1986;81:525-31.

3. Burch HB. Evaluation and management of the solid thyroid nodule. EndocrinolClin North Am.1995;24:663-710.

4. Gershengorn MC, McClung MR, Chu EW. Fine needle aspiration cytology in the preoperative diagnosis of thyroid nodules. Ann Intern Med.1993;118:282-9.

5. Kamalajitkaur, nishy S, Bapna AS, A comparative study of fine needle aspiration cytology,USG and radionucleotide scan in management of thyroid nodule: Indian Journal of Otolaryngology and Head and neck surgery, April-june2002;54:96-101.

6. Giuffrida D, Gharib H. Controversies in the management of cold, hot and occult thyroid nodules. Am J Med.1995;99:64250.

7. Cappel RJ, Bouvy ND, Bonjer HJ, Muiswinkel JM et al. Fine needle aspiration of thyroid nodules: how accurate it is and what are the causes of discrepant cases? Cytopathology. 2001; 12:399-405.

8. La Rosa GL, Belfiore A, Giuffrida D, et a. Evaluation of the fine needle aspiration biopsy in the preoperative selection of cold thyroid nodules. Cancer.1991;67:2137-41.

9. Bouvet M field Man J. Surgical Management of thyroid nodule, Laryngoscope. 1992;102:1353- 56.

10. GritzmannN,Koischwitz D, et al. Sonography of the thyroid and parathyroid glands. RadiolClini North Am 2000;38: 1131-45.

11. Kumori T, Shinya H, Satomi T, et al. Management of nodular goiters and their operative indications. SurgToday. 2003; 30:722- 6 .

12. Borgohain R, Kumar R, Chatterjee P. A study of cyto-histological correlation in the diagnosis of thyroid swelling. IOSR Journal of Dental and Medical Sciences. Nov 2014;13(11):46-9.

13. Srivastava CS, Saxena A. Study of clinical and epidemiological profile of thyroid swelling. International Journal of Medical Research and Review. 2015;3(8):7-11.

14. Nagarkar R, Roy S. Incidence of thyroid disorders in India: an institutional retrospective analysis. International 
Journal of Dental and Medical Specialty. 2015:2(2)17-9.

15. Goel MM, Budhwar P. Fine needle aspiration and immunocytochemistry in tuberculous thyroiditis. Acta Cytol. 2008;52(5):602-6. 